\title{
Correspondence
}

\section{The London Dysmorphology Database}

SIR,

The paper by Brandl and Grimm ${ }^{1}$ in this issue, describing the creation of a chromosome supplement to the London Dysmorphology Database, provides a useful opportunity to report on recent progress. The initial purpose of the database was to help experienced dysmorphologists to arrive at the correct diagnosis in difficult cases with multiple congenital anomalies. The design and scope of the database is described elsewhere, ${ }^{2}$ but it is worth emphasising that our goal has been to provide the dysmorphologist with a list of possible diagnoses for a particular case, with references, rather than have the computer make the diagnosis alone. We feel that with very rare conditions, only an expert can decide whether a diagnosis is correct, by comparison of clinical features in the light of extensive clinical experience. Thus, the database has not been designed as a tool for the non-specialist.

Another aim has been to detect new patterns of malformation and to this end we have created a database of undiagnosed cases and have developed methods to group cases, in order to recognise 'new' conditions. ${ }^{3}$

Finally, the development of the literature database has led to other projects, involving the creation of databases covering other branches of clinical genetics.

\section{The literature and undiagnosed case databases}

The literature database now contains information on over 1500 non-chromosomal multiple malformation syndromes with over 5000 references. Eighty-five units around the world are using the database. Updates appear once a year in April. Users also obtain the database of undiagnosed cases (now over 650), to which they can add their own, and search for similar cases. If a match is found, the two contributing physicians are put in touch with one another. We have found that use of the programme has lead to a precise diagnosis in many cases, and has helped us to recognise 'new' syndromes. ${ }^{4-6}$ The methods developed for grouping undiagnosed cases as a whole ${ }^{3}$ have also lead to the recognition of 'new' syndromes. $^{7}$

We are collaborating with other groups, principally POSSUM (Danks, Melbourne), who are using, with our permission, our data to expand their systems. Nevertheless, the database will continue in its present form as an independent system. We feel that different groups are approaching the problem in different ways and, whereas one approach may eventually prove to be the best, alternative strategies should be tried.

In the longer term we are working towards adding photographs, stored on the computer, to the system, but we are waiting for the appropriate technology to become cheaper before releasing this version of the database.

\section{Development of other databases}

As has been demonstrated in this issue of the journal, the database structure can be used for developing other databases. We are collaborating with Professor Albert Schinzel (Zürich) who is putting the second edition of his Catalogue of unbalanced chromosome aberrations in man into the database format. This will probably be complete in 1987 and we hope to include it in our database with the agreement of Professor Schinzel.

One of us (Dr Baraitser) is developing a database of neurological abnormalities, which again should be available in 1987. A database of mouse malformation syndromes has been completed, which we hope will be useful for recognising mouse/human homologies for the purpose of gene mapping and other comparative studies.

\section{Conclusions}

The London Dysmorphology database was started as an aid to diagnosis of established conditions and the recognition of 'new' syndromes. It has now expanded to include other databases and it is, in itself, a valuable research tool. We would be happy to receive further suggestions for the development of the database, or for collaboration on further projects.

Robin M Winter and Michael Baraitser

The Kennedy-Galton Centre for Clinical Genetics, Harperbury Hospital, Radlett, Herts WD7 9HQ; and Clinical Genetics Unit, Institute of Child Health. 30 Guilford Street, London WCIN IEH. 
References

1 Brandl J, Grimm T. A chromosome supplement to the London Dysmorphology Database. J Med Genet 1987:24:497-8.

2 Winter RM, Baraitser M, Douglas JM. A computerised data base for the diagnosis of rare dysmorphic syndromes. J Med Genet 1984;21:121-3.

${ }^{3}$ Winter RM, Clarke RD, Ashley K, Gibbs G. A combinatorial method for grouping cases with multiple malformations. J Med Genet (in press).

${ }^{4}$ Baraitser M, Winter RM. Iris coloboma, ptosis, hypertelorism and mental retardation: a new syndrome. $J$ Med Genet (in press).

5 Hurst JA, Winter RM, Baraitser M. A syndrome of short stature, mental retardation, delayed puberty, haemolytic anaemia and dysmorphic facial features. A possible further report of aldolase A deficiency. Am J Med Genet (in press).

${ }^{6}$ Hurst JA, Marcowiccz M, Kumar D, Brett EM. Hirschsprung's discase, microcephaly and iris coloboma: a new syndrome of defective neuronal migration. $J$ Med Genet (in press).

${ }^{7}$ Hurst JA, Winter RM, Baraitser M. Osteodysplastic primordial dwarfism - a further variant identified by computer matching. Am J Med Genet (in press).

\section{Pericentric inversion and sterility}

SIR,

In January 1986 we published the first familial case of pericentric inversion of chromosome 1 involving the whole of the short arm and associated with sterility in two brothers. ${ }^{1}$

The inherited transmission of this chromosomal anomaly was shown by the cytogenetic study of the proband's mother who is a carrier of the inversion. Later, another brother of those reported contacted our department, worried about his possible infertility. The karyotype showed the same pericentric inversion, $46, X Y$, inv(1)(p36.3q12), as in his brothers and he had severe oligozoospermia (about 200000 per ml).

Therefore, we have three sterile men with the same maternally transmitted chromosome abnormality. This may be interpreted as further evidence of the susceptibility of spermatogenesis to structural chromosome rearrangements.

Alberto Barros* + , M Carmo Tavares*, M Paula Gomes*, and M Purificação Tavares* *Department of Medical Genetics, Faculty of Medicine, University of Oporto; and †Department of Obstetrics, S João Hospital, Oporto, Portugal.

\footnotetext{
Reference

1 Barros A, Tavares MC, Gomes MP, Tavares MP. Familial inv(1)(p36-3q12) associated with sterility. J Med Genet 1986;23 90-1.
}

The craniocardioskeletal syndrome and the Noonain like short stature syndrome are possibly the sames entity

SIR,

Baraitser and Patton $^{1}$ recently described Noonan-like short stature syndrome (possibly new in four children (three female, one male), presentirf with sparse hair, mildly slow development, posto eriorly rotated ears, short nose, low hair line, and shield shaped chest. Other features included: heaff murmur and prominent philtrum (cases 1 and $2{ }^{5}$ hypertrophic cardiomyopathy (case 4), pectự excavatum (case 1), and increased head circumfen ence with moderate hydrocephalus, low set ear $\$$ and narrowing of the interpedicular distances ber tween L1 and L5 (case 3). Many of these features are similar to those present in a syndrome describe by our group,$^{23}$ including short stature, delayed psychomotor development, scanty hair coarse face (cases 2 and 4 of Baraitser and Patton are remarle ably similar to cases C and D of our reportकf flattened nasal bridge, short nose with anterverted nostrils, long philtrum, low set, posteriorly rotateep ears, short and wide thorax, cardiac murmui cubitus valgus, and delayed bone age.

There are, however, some discordant feature present in our cases, such as mild exophthalmo cutis laxa, and wrinkled palms and soles (washeg woman's hands).

We think that it is useful to compare the clinic picture as well as the radiographical data in order to obtain the best delineation of the syndrome, which we have assumed to be an autosomal domina $\overline{\bar{y}}$ disorder, mainly because of the advanced parenta age in our cases. Recently, McKusick ${ }^{4}$ cataloguea this syndrome as a separate entity (entry 11462)

José Sánchez Corona and José Mariá Cantô División de Genéticả Unidad de Investigación Biomédicog Centro Médico de Occidente Instituto Mexicano del Seguro Socia Apartado Postal 1-383\% Guadalajara, Jalisco, Mexico.

References

1 Baraitser M. Patton MA. A Noonan-like short stature drome with sparse hair. J Med Genet 1986;23:161-4.

2 Cantú JM, Sánchez-Corona J, Hernández A, Nazará Z. Garc Cruz D. Individualization of a syndrome with mental deficienco macrocranium, peculiar facies, and cardiac and skelet anomalies. Clin Genet 1982;22:172-9.

${ }^{3}$ Sánchez-Corona J, Cantú JM. Dermo-facio-cardio-skeletal sy ${ }_{B}$ drome. Birth defects encyclopedia. New York: Alan R Liss (\$ष्ठ press).

${ }^{4}$ McKusick VA. Mendelian inheritance in man. 7 th ed. Baltimo Johns Hopkins University Press, 1986. 